\title{
Prediksi Brand Experience Dan Perceived Quality Terhadap Brand Loyalty: Brand Trust Sebagai Variabel Mediasi
}

\author{
Winnie dan Keni \\ Universitas Tarumanagara, Jakarta \\ Email: Winnie.115160288@stu.untar.ac.id
}

\begin{abstract}
The purpose of this research is to examine whether 1) brand experience can predict brand loyalty. 2) perceived quality can predict brand loyalty. 3) brand experience can predict brand trust. 4) brand trust can predict brand loyalty. 5) brand trust mediates the prediction brand experience on brand loyalty. Sample was selected using convenience sampling method amounted to 150 respondents. The result of this study show that brand experience has significant effect to predict brand loyalty, brand experience has significant effect to predict brand trust, perceived quality and brand trust have significant effect to predict brand loyalty, and brand trust mediates the prediction of brand experience on brand loyalty.
\end{abstract}

Keywords: Brand Experience, Perceived Quality, Brand Trust, Brand Loyalty

\begin{abstract}
Abstrak: Tujuan dari penelitian ini adalah untuk menguji apakah 1) pengalaman merek dapat memprediksi loyalitas merek. 2) persepsi kualitas dapat memprediksi loyalitas merek. 3) pengalaman merek dapat memprediksi kepercayaan merek. 4) kepercayaan merek dapat memprediksi loyalitas merek. 5) kepercayaan merek memediasi prediksi pengalaman merek pada loyalitas merek. Sampel dipilih menggunakan metode convenience sampling berjumlah 150 responden. Hasil penelitian ini menunjukkan bahwa pengalaman merek memiliki pengaruh signifikan untuk memprediksi loyalitas merek, pengalaman merek memiliki pengaruh signifikan untuk memprediksi kepercayaan merek persepsi kualitas dan kepercayaan merek memiliki pengaruh signifikan untuk memprediksi loyalitas merek, dan kepercayaan merek memediasi prediksi pengalaman merek pada loyalitas merek.
\end{abstract}

Kata kunci: Pengalaman Merek, Persepsi Kualitas, Kepercayaan Merek, Loyalitas Merek

\section{LATAR BELAKANG}

Di zaman modern seperti sekarang, fashion telah menjadi bagian dari gaya hidup (life style) yang di minati. Fashion menjadi hal penting yang di minati oleh berbagai kalangan umur, baik muda maupun tua. Berbagai fashion brand yang bermunculan menjadi tanda berkembangnya bisnis fashion di dunia. Pada saat ini, kompetisi antar fashion brand sangat terasa. Hal ini dapat dilihat dari beberapa gerakan yang dilakukan, contohnya dengan menambah "seasons" yang berarti menambah frekuensi pergantian produk yang dijual di toko. Sebuah fashion brand perlu untuk meningkatkan popularitasnya agar dikenal berbagai kalangan, dari yang muda sampai tua. Sampai awal tahun 2017, Global Fashion Brands mengalami kesuksesan di pasar Indonesia, situasi ini terjadi karena bertumbuhnya permintaan pakaian yang meningkat (Kompasiana, 2017). Dengan melonjaknya konsumen 
dari Global Fashion Brands, maka perusahaan perlu menjaga pelanggan agar tidak beralih ke merek lain dengan meningkatkan brand loyalty perusahaan.

Menurut Aaker (1991), brand loyalty merupakan keterikatan yang dimiliki pelanggan terhadap suatu merek. Fokus dari aktivitas bisnis pada saat ini bukan hanya tertuju untuk menarik konsumen baru, akan tetapi juga mempertahankan konsumen lama. Berdasarkan penelitian terdahulu, terdapat banyak faktor yang mempengaruhi brand loyalty. Su dan Chang (2017) menunjukkan bahwa brand awareness, perceived quality, perceived value, brand personality, organizational associations, dan brand uniqueness berpengaruh signifikan terhadap brand loyalty. Khan et al., (2016) menyatakan bahwa brand experiences dan brand satisfaction memiliki pengaruh positif terhadap brand loyalty. Su (2016) menyatakan bahwa brand awareness, brand personality, perceived quality, dan perceived value berpengaruh signifikan terhadap brand loyalty. Penelitian Huang (2017) menunjukkan bahwa brand trust dan brand love berpengaruh signifikan terhadap brand loyalty. Lebih lanjut, Huang (2017) menyatakan bahwa brand trust dapat memediasi brand experience terhadap brand loyalty.

\section{KAJIAN TEORI}

Penelitian ini mengacu pada brand resonance model oleh Keller (2013), yang menjelaskan mengenai hubungan pelanggan dengan suatu merek yang meliputi perasaan pelanggan tentang sejauh mana pelanggan merasa bahwa merek tersebut memiliki kecocokan dengan pelanggan. Model ini mempertimbangkan bagaimana positioning merek memengaruhi apa yang dipikirkan, dirasakan, dan dilakukan pelanggan serta sejauh mana mereka beresonansi atau terhubung dengan suatu merek. Resonansi dicirikan dalam hal kedalaman ikatan psikologis yang dimiliki pelanggan dengan merek, serta tingkat aktivitas yang ditimbulkan oleh loyalitas pelanggan. Brand resonance model menunjukkan bahwa loyalitas pelanggan terhadap suatu merek dapat dicapai melalui dua rute yaitu secara emosional dan rasional. Brand judgement dan brand performance merupakan rute rasional, sedangkan brand imagery dan brand feelings merupakan rute emosional. Variabel yang dipilih dalam penelitian ini yaitu brand experience dan brand trust yang merupakan rute rasional serta perceived quality yang merupakan rute emosional yang dilewati untuk mencapai loyalitas pelanggan.

Brand Loyalty. Brand loyalty merupakan loyalitas terhadap suatu merek. Ada beberapa definisi brand loyalty yang dikemukakan oleh para ahli. Menurut Oliver (1999, p. 34), menyatakan brand loyalty merupakan: "a deeply held commitment to rebuy or re-patronize a preferred product or service consistently in the future, despite situational influences and marketing efforts having potential to cause switching behaviour." Menurut Aaker (1991, p. 44), brand loyalty adalah: "a measure of the attachment that a customer has to a brand." Menurut Liu (2007, p. 20), menjelaskan bahwa brand loyalty adalah: "positive feeling toward the brand and intense dedication to purchase the same product/ service repeatedly now and in the future from the same brand, regardless competitor's action or changes in the environment".

Brand Experience. Menurut Brakus et al. (2009, p. 53) brand experience dapat didefinisikan sebagai: "subjective, internal consumer responses (sensation, feelings, and cognitions, and behavioral responses), evoked by brand-related stimuli that are part of a 
brand's design and identity, packaging, communications, and environments". Menurut Alloza (2008, p. 373) menjelaskan bahwa brand experience adalah: "the perception of the consumers, at every moment of contact they have with the brand, whether it is in the brand images projected in advertising, during the first personal contact, or the level of quality concerning the personal treatment they receive”. Morgan-Thomas dan Veloutsou (2013, p. 22) menyatakan bahwa brand experience berdasarkan online brand adalah: "an individual's internal subjective response to the contact with the online brand".

Perceived Quality. Menurut Zeithaml (1988, p. 3) menyatakan bahwa perceived quality adalah: "the consumer's judgment about a product's overall excellence or superiority". Menurut Aaker (1991, p. 84) menyatakan bahwa perceived quality adalah: "the customer's perception of the overall quality or superiority of a product or service with respect to its intended purpose,relative to alternatives". Selanjutnya Netemeyer et al. (2004, p. 210) menyatakan bahwa perceived quality adalah: "the customer's judgment of the overall excellence, esteem, or superiority of a brand (with respect to its intended purposes) relative to alternative brand(s)".

Brand Trust. Menurut Ha dan Perks (2005, p. 443) menyatakan bahwa brand trust adalah "feeling of security held by the consumer in his/her interaction with the brand, that it is based on the perceptions that the brand is reliable and responsible for the interests and welfare of the consumer". Chaudhuri dan Holbrook (2001, p. 82) menjelaskan brand trust adalah: "the willingness of the average consumer to rely on the ability of the brand to perform its stated function”. Rousseau et al. (1998, p. 395) menjelaskan trust adalah “...a psychological state comprising the intention to accept vulnerability based upon the behaviour of positive expectations of the intentions of or behaviour of another".

\section{Kaitan antara Brand Experience, Perceived Quality dan Brand Loyalty}

Kaitan antara brand experience dan brand loyalty. Pelanggan akan menjadi loyal terhadap suatu merek ketika mendapatkan brand experience mengenai keunggulan apa yang dirasakan mengenai merek tersebut (Koufaris et al., 2002). Pengalaman yang positif mengenai suatu merek akan mendorong keinginan pelanggan mengulangi hal yang sama untuk mendapatkan pengalaman serupa. Adanya kaitan antara brand experience dan brand loyalty telah ditemukan dalam penelitian sebelumnya yang dilakukan oleh Khan et al. (2016), Ramaseshan dan Stein (2014), dan Khan dan Rahman (2016).

Kaitan antara perceived quality dan brand loyalty. Perceived quality merupakan elemen paling relevan dari merek yang unggul di pasar industri (Michell et al., 2001). Klien cenderung enggan untuk beralih ke merek lain jika tingkat kualitas saat ini dianggap memadai (Sharp, 1996). Adanya kaitan antara perceived quality dan brand loyalty telah ditemukan dalam penelitian sebelumnya yang dilakukan oleh $\mathrm{Su}$ (2016), Hulten dan Tarnovskaya (2019), dan Nguyen et al. (2011).

Kaitan antara Brand Experience dan Brand Trust. Pelanggan akan merasa percaya pada suatu merek yang mereka yakini ketika ia mendapatkan pengalaman yang relevan dengan pelanggan, yang akan mengembangkan kepercayaan pada merek (Delgado-Ballester \& Munuera-Aleman, 2001). Kepercayaan berkembang dari pengalaman masa lalu dan 
interaksi sebelumnya (Rempel et al., 1985). Setelah berinteraksi dengan suatu merek, konsumen menjadi lebih akrab dan berpengetahuan tentang merek, yang mengarah pada peningkatan kepercayaan merek (Garbarino \& Johnson, 1999). Adanya kaitan antara brand experience dan brand trust telah ditemukan dalam penelitian sebelumnya yang dilakukan oleh Huang (2017), Khan dan Rahman (2016), dan Yu dan Yuan (2019).

Kaitan antara Brand Trust dan Brand Loyalty. Brand trust merupakan pendorong utama terciptanya brand loyalty (Chaudhuri \& Holbrook, 2001). Pelanggan yang puas akan menjadi pelanggan yang loyal ketika memiliki tingkat kepercayaan pada merek yang tinggi (Ha, 2004). Adanya kaitan antara brand trust dan brand loyalty telah ditemukan dalam penelitian sebelumnya yang dilakukan oleh Huang (2017), Chinomona (2016), dan Khan dan Rahman (2016).

Brand Trust memediasi kaitan antara Brand Experience dan Brand Loyalty. Huang (2017) mengungkapkan bahwa brand trust merupakan variabel mediasi dan memiliki pengaruh dalam mempengaruhi hubungan antara brand experience terhadap brand loyalty. Dengan adanya kepercayaan pelanggan terhadap suatu merek maka akan memicu stimuli pelanggan untuk merasakan hal positif mengenai suatu merek sehingga hal tersebut akan mendorong pelanggan untuk loyal terhadap suatu merek. Hasil penelitian menunjukkan bahwa brand trust dapat memediasi hubungan antara brand experience terhadap brand loyalty.

Berdasarkan pemaparan di atas, maka model dan hipotesis penelitian yang digunakan dalam penelitian ini adalah sebagai berikut.

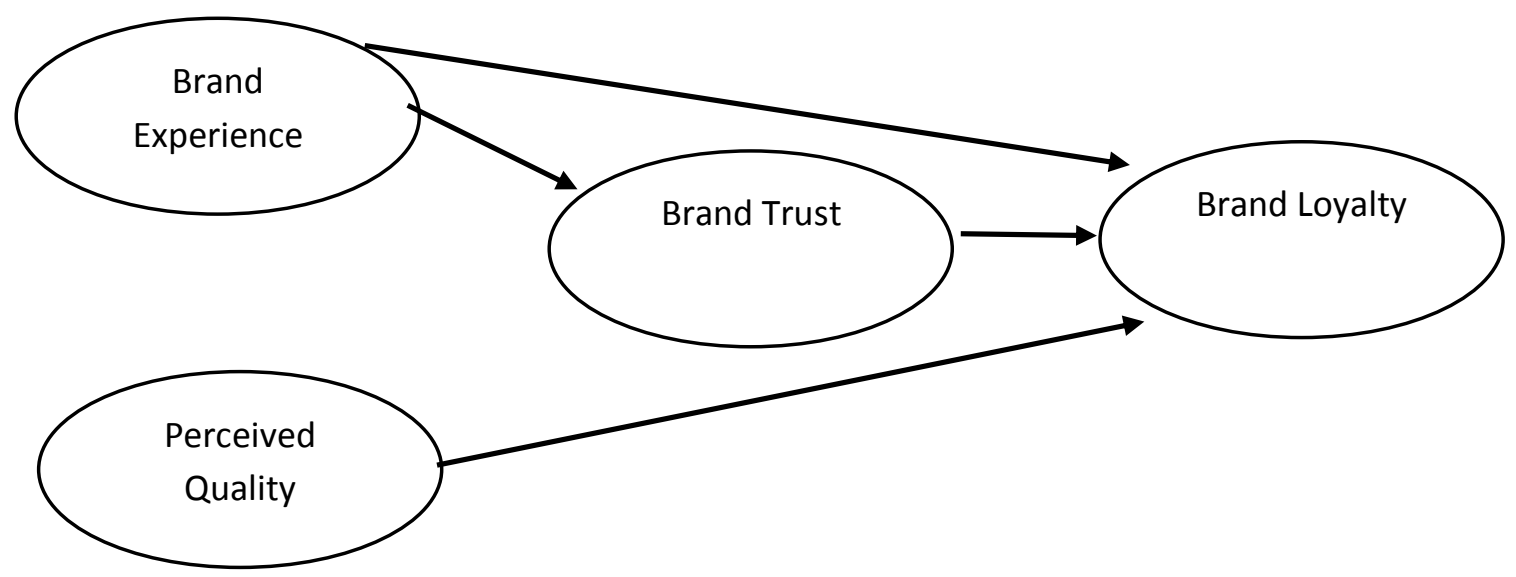

Gambar 1. Model Penelitian

H1a: Brand experience dapat memprediksi secara positif terhadap brand loyalty.

H1b: Perceived quality dapat memprediksi secara positif terhadap brand loyalty.

$\mathbf{H}_{2}$ : Brand Experience dapat memprediksi secara positif terhadap brand trust.

H3: Brand trust dapat memprediksi secara positif terhadap brand loyalty.

H4: Brand trust dapat memediasi prediksi secara positif brand experience terhadap brand loyalty. 


\section{METODOLOGI}

Penelitian ini merupakan penelitian deskriptif cross sectional. Sampel diambil menggunakan metode nonprobability sampling, tepatnya dengan menggunakan teknik convenience sampling. Hal ini dilakukan agar pengumpulan data dapat dilakukan dengan mudah dan cepat. Jumlah responden yang diambil oleh peneliti sebanyak 150 responden.

Pengukuran variabel-variabel dalam penelitian ini mengacu pada penelitian sebelumnya antara lain sebagai berikut:

Variabel

\begin{tabular}{|c|c|c|}
\hline Variabel & Indikator & Acuan \\
\hline Brand Loyalty & 5 item & $\begin{array}{c}\text { Chaudhuri dan Holbrook } \\
\text { (2001), Ha et al. (2011), } \\
\text { Wirtz et al. }(2007), \text { Zeithaml } \\
\text { et al. }(1996)\end{array}$ \\
\hline Brand Experience & 5 item & Brakus et al. (2009) \\
\hline Perceived Quality & 5 item & $\begin{array}{c}\text { Yoo et al. (2000), Buil et al. } \\
\text { (2008), Yoo dan Donthu } \\
\text { (2001), Netemeyer et al. } \\
\text { (2004) }\end{array}$ \\
\hline Brand Trust & 5 item & $\begin{array}{c}\text { Chaudhuri dan Holbrook } \\
\text { (2001), Chen (2010) }\end{array}$ \\
\hline
\end{tabular}

\section{HASIL UJI STATISTIK}

Hasil Uji validitas dalam penelitian ini dikatakan valid dalam penelitian ini berdasarkan nilai AVE yang diperoleh bernilai lebih besar dari $0,5(>0,5)$ serta nilai loading factor dari setiap indikatornya lebih besar dari $0,7(>0,7)$. Hasil uji reliabilitas dalam penelitian ini dikatakan reliabel berdasarkan hasil analisis dengan menggunakan pendekatan Cronbach's Alpha maupun Composite Reliability pada item untuk setiap variabel yang lebih dari 0,7 . Sedangkan, discriminant validity terdiri dari analisis fornelllarcker dan cross loading. Hasil yang diperoleh dalam penelitian ini menunjukkan bahwa nilai yang diperoleh telah memenuhi syarat cross-loadings dan fornell-larcker.

$\mathrm{R}^{2}$ digunakan untuk mengukur seberapa besar variabel brand experience, perceived quality, dan brand trust dapat menjelaskan variabel brand loyalty. nilai $R$ square sebesar 0,521 menjelaskan bahwa sebesar $52,1 \%$ dari variabel mediasi yaitu brand trust dapat dijelaskan oleh variabel-variabel yang terdapat pada penelitian ini, sisanya sebesar $47,9 \%$ dapat dijelaskan oleh variabel-variabel lain yang tidak diteliti dalam penelitian ini. Selanjutnya sebesar 0,691 nilai $R$ square dari brand loyalty menjelaskan bahwa sebesar $69,1 \%$ dari variabel brand loyalty dapat dijelaskan oleh variabel yang diteliti dalam penelitian ini, sisanya sebesar 30,9\% dapat dijelaskan oleh variabel-variabel lain yang tidak diteliti dalam penelitian ini. Selanjutnya, hasil pengujian $\mathrm{Q}^{2}$ menunjukan nilai sebesar 0,307 untuk brand trust dan 0,394 untuk brand loyalty yang artinya nilai predictive relevance $\left(\mathrm{Q}^{2}\right)$ dalam penelitian ini lebih besar dari 0 (nol). 
Winnie dan Keni: Prediksi Brand Experience Dan Perceived Quality Terhadap Brand...

Hasil analisis data secara singkat dapat dilihat pada Tabel 1.

Tabel 1. Hasil Pengujian Hipotesis

\begin{tabular}{lccc}
\multicolumn{1}{c}{ Variabel } & Path Coefficient & t-statistics & p-values \\
\hline Brand Experience => Brand Loyalty & 0,508 & 5,215 & 0,000 \\
\hline Brand Experience => Brand Trust & 0,722 & 15,072 & 0,000 \\
\hline Brand Trust => Brand Loyalty & 0,215 & 2,166 & 0,030 \\
\hline Perceived Quality => Brand Loyalty & 0,179 & 2,108 & 0,035 \\
\hline $\begin{array}{l}\text { Brand Experience => Brand Trust => } \\
\text { Brand Loyalty }\end{array}$ & 0,155 & 2,003 & 0,045 \\
\hline
\end{tabular}

Berdasarkan pada hasil dari pengujian bootstrapping yang ditampilkan pada Tabel 1 di atas, maka terdapat persamaan untuk variabel brand loyalty yang dapat dijelaskan sebagai berikut: $\mathrm{BL}=0,508 \mathrm{BE}+0,215 \mathrm{BT}+0,179 \mathrm{PQ}$. Berdasarkan persamaan tersebut, dapat dijelaskan bahwa variabel brand experience merupakan prediktor terbesar dan memiliki arah positif terhadap variabel brand loyalty yaitu sebesar 0,508. Brand trust sebagai prediktor terbesar kedua dan memiliki arah positif dengan nilai sebesar 0,215. Perceived quality sebagai prediktor ketiga dan berarah positif yang memiliki nilai path coefficient terendah dibandingkan variabel lainnya dengan nilai sebesar 0,179 . Selanjutnya, terdapat nilai mediasi brand trust terhadap brand experience dan brand loyalty sebesar 0,155 yang memiliki arah positif.

Pengujian lainnya dalam penelitian ini yaitu pengujian effect size. Hasilnya menunjukan bahwa dapat dijelaskan bahwa variabel brand experience memiliki efek perubahan yang besar terhadap brand trust yaitu dengan nilai sebesar 1,090, dan efek yang rendah terhadap brand loyalty yaitu sebesar 0,263. Terdapat juga variabel brand trust yang memberikan efek perubahan yang kecil terhadap brand loyalty dengan nilai efek perubahan sebesar 0,066, dan variabel perceived quality yang memberikan efek perubahan kecil terhadap brand loyalty dengan nilai efek perubahan sebesar 0,036. Selain itu, dilakukan pula pengujian goodness of fit (GoF). Hasil perhitungan menunjukan hasil yang menyatakan model yang digunakan dalam penelitian ini memiliki nilai GoF sebesar 0,6134. Menurut Wetzels et al. (2009) menyatakan bahwa model yang digunakan dalam penelitian ini memiliki kecocokan atau (Goodness of Fit) yang tergolong besar 0,6134 (> $0,36)$.

\section{DISKUSI}

Berdasarkan pada hasil pengujian hipotesis yang pertama bagian a $\left(\mathrm{H}_{1 \mathrm{a}}\right)$ menunjukan bahwa brand experience terbukti dapat memprediksi secara positif brand loyalty, sehingga dapat disimpulkan bahwa $\mathrm{H}_{1 \mathrm{a}}$ tidak ditolak. Hasil dari pengujian hipotesis tersebut sesuai dengan penelitian Khan et al. (2016), Ramaseshan dan Stein (2014), dan Khan dan 
Rahman (2016) yang menyatakan hal serupa bahwa brand experience secara positif dapat meningkatkan brand loyalty dari pelanggan. Pengalaman yang positif dan unik yang didapatkan mengenai suatu merek akan mendorong keinginan pelanggan mengulangi hal yang sama untuk mendapatkan pengalaman serupa. Pelanggan yang memiliki pengalaman yang positif mengenai suatu merek lebih mungkin untuk melakukan pembelian kembali dan akan merekomendasikannya kepada orang lain.

Selanjutnya, Berdasarkan pada hasil pengujian hipotesis yang pertama bagian $b\left(\mathrm{H}_{1 \mathrm{~b}}\right)$ menunjukan bahwa variabel perceived quality terbukti dapat memprediksi secara positif brand loyalty, sehingga dapat disimpulkan bahwa $\mathrm{H}_{1 \mathrm{~b}}$ tidak ditolak. Hasil dari pengujian hipotesis tersebut sesuai dengan penelitian Su (2016), Hulten dan Tarnovskaya (2019), dan Nguyen et al. (2011) yang menyatakan hal serupa bahwa perceived quality secara positif dapat meningkatkan brand loyalty dari pelanggan. Penilaian pelanggan terhadap kualitas yang dirasakan secara umum akan mempengaruhi loyalitas pelanggan terhadap merek tersebut. Persepsi kualitas yang dibangun perusahaan akan mendorong pelanggan untuk melakukan pembelian kembali. Pelanggan tidak akan beralih ke merek lain jika produk tersebut sesuai dengan kebutuhannya.

Berdasarkan pada hasil pengujian hipotesis yang kedua $\left(\mathrm{H}_{2}\right)$ menunjukkan bahwa variabel brand experience terbukti dapat memprediksi secara positif brand trust, sehingga dapat disimpulkan bahwa $\mathrm{H}_{2}$ tidak ditolak. Hasil dari pengujian hipotesis tersebut sesuai dengan penelitian Huang (2017), Khan dan Rahman (2016), dan Yu dan Yuan (2019) yang menyatakan hal serupa bahwa brand experience secara positif dapat meningkatkan brand trust dari pelanggan. Pelanggan akan merasa percaya pada suatu merek yang mereka yakini ketika pelanggan mendapatkan pengalaman yang relevan. Hal ini yang akan mengembangkan kepercayaan pada merek. Setelah berinteraksi dengan suatu merek, pelanggan menjadi lebih akrab dan berpengetahuan tentang merek, yang mengarah pada peningkatan kepercayaan merek.

Berdasarkan pada hasil pengujian hipotesis yang ketiga $\left(\mathrm{H}_{3}\right)$ menunjukkan bahwa variabel brand trust terbukti dapat memprediksi secara positif brand loyalty, sehingga dapat disimpulkan bahwa $\mathrm{H}_{3}$ tidak ditolak. Hasil dari pengujian hipotesis tersebut sesuai dengan penelitian Huang (2017), Chinomona (2016), dan Khan dan Rahman (2016) yang menyatakan hal serupa bahwa brand trust secara positif dapat meningkatkan brand loyalty dari pelanggan. Kepercayaan terhadap suatu merek merupakan suatu faktor yang dapat mempengaruhi loyalitas pelanggan terhadap merek. Semakin tinggi kepercayaan terhadap suatu merek akan semakin meningkatkan loyalitas pelanggan tersebut.

Berdasarkan pada hasil pengujian hipotesis yang keempat $\left(\mathrm{H}_{4}\right)$ menunjukkan bahwa variabel brand trust terbukti dapat memprediksi secara positif mediasi antara brand experience terhadap brand loyalty, sehingga dapat disimpulkan bahwa $\mathrm{H}_{4}$ tidak ditolak. Hasil dari pengujian hipotesis tersebut sesuai dengan penelitian Huang (2017), yang menyatakan hal serupa bahwa variabel brand trust dapat memprediksi mediasi hubungan antara brand experience terhadap brand loyalty dari pelanggan. Dalam penelitian ini, dijelaskan bahwa brand trust merupakan variabel mediasi dan memiliki pengaruh dalam mempengaruhi hubungan antara brand experience terhadap brand loyalty. Dengan adanya kepercayaan pelanggan terhadap suatu merek maka akan memicu stimuli pelanggan untuk merasakan hal positif mengenai suatu merek sehingga hal tersebut akan mendorong pelanggan untuk loyal terhadap suatu merek. 


\section{PENUTUP}

Dari hasil uraian dan analisis yang telah dilakukan, dapat diketahui bahwa brand experience, perceived quality, dan brand trust dapat memprediksi secara positif terhadap brand loyalty, brand experience dapat memprediksi secara positif terhadap brand trust, dan brand trust dapat memediasi secara positif brand experience terhadap brand loyalty. Peneliti menyarankan Global Fashion Brands perlu untuk terus berinovasi memberikan brand experience yang berbeda dalam hal berbelanja serta terus menambah variasi terhadap pemenuhan kebutuhan pelanggan. Untuk penelitian selanjutnya, disarankan agar memperluas jangkauan pengambilan sampel dan wilayah yang dicakupi, sehingga dapat memperoleh data dengan karakteristik responden yang berbeda beda dan disarankan juga untuk dapat menambah dan mengembangkan variabel-variabel lainnya yang dapat memprediksi jauh lebih baik lagi terhadap brand loyalty.

\section{DAFTAR PUSTAKA}

Aaker, D.A. (1991), Managing Brand Equity: Capitalizing on the Value of a Brand Name, The Free Press, New York, NY.

Alloza, A. (2008), "Brand engagement and brand experience at BBVA, the transformation of a 150 years old company", Corporate Reputation Review, Vol. 11 No. 4, pp. 371379.

Brakus, J., Schmitt, B. and Zarantonello, L. (2009), "Brand experience: what is it? how is it measured? does it affect loyalty?", Journal of Marketing, Vol. 73 No. 3, pp. 52-68.

Chaudhuri, A. and Holbrook, M.B. (2001), "The chain of effects from brand trust and brand affect to brand performance: the role of brand loyalty", Journal of Marketing, Vol. 65 No. 2, pp. 81-93.

Delgado-Ballester, E. and Munuera-Alemán, J.L. (2001), "Brand trust in the context of consumer loyalty", European Journal of Marketing, Vol. 35 Nos 11/12, pp. 12381258.

Garbarino, E. and Strahilevitz, M. (2004), "Gender differences in the perceived risk of buying online and the effects of receiving a site recommendation", Journal of Business Research, Vol. 57 No. 7, pp. 768-775.

Ha, H.Y. (2004), "Factors influencing consumer perceptions of brand trust online", Journal of Product \& Brand Management, Vol. 13 No. 5, pp. 329-342.

Ha, H.Y. and Perks, H. (2005), "Effects of consumer perceptions of brand experience on the web: brand familiarity, satisfaction and brand trust", Journal of Consumer Behaviour, Vol. 4 No. 6, pp. 438-452.

Highlight media. (2018). Simak Kisah Sukses H\&M, Fashion Brand Terkemuka Asal Swedia. https://highlight.id/kisah-cerita-sejarah-asal-usul-perusahaan-merekbranded-fashion-h-and-m-swedia/

Kompas. (2018). Manfaatkan Kanal Online Penjualan H\&M Melonjak. https://ekonomi.kompas.com/read/2018/09/28/071236826/manfaatkan-kanal-onlinepenjualan-hm-melonjak

Koufaris, M., Kambil, A. and LaBarbera, A. (2002), "Consumer behavior in web-based commerce: an empirical study", International Journal of Electronic Commerce, Vol. 6 No. 2, pp. 115-138. 
Liu, Y. (2007), "The long-term impact of loyalty programs on consumer purchase behavior and loyalty', Journal of Marketing, 71 (4), pp. 19-35.

Michell, P., King, J. and Reast, J. (2001), "Brand values related to industrial products", Industrial Marketing Management, Vol. 30No. 5, pp. 415-425.

Morgan-Thomas, A. and Veloutsou, C. (2013), "Beyond technology acceptance: brand relationships and online brand experience", Journal of Business Research, Vol. 66 No. 1, pp. 21-27

Netemeyer, R.G., Krishnan, B., Pullig, C., Wang, G., Yagci, M., Dean, D., Ricks, J. and Wirth, F. (2004), "Developing and validating measures of facets of customer-based brand equity", Journal of Business Research, Vol. 57 No. 12, pp. 209-224.

Oliver, R.L. (1999), "Whence consumer loyalty?", The Journal of Marketing, 63, Special Issue, pp. 33-44

Rempel, J.K., Holmes, J.G. and Zanna, M.P. (1985), “Trust in close relationships”, Journal of Personality and Social Psychology, Vol. 49 No. 1, pp. 95-112.

Rousseau, D.M., Sitkin, S., Burt, R.S., \& Camerer, C.F. 1998.'Not So Different After All: a Cross-discipline View of Trust', Academy of Management Review,vol. 23, no. 3, pp. 393-404

Sharp, B. (1996), "Brand equity and market-based assets of professional service firms", Journal of Professional Services Marketing, Vol. 13 No. 1, pp. 3-13.

Zeithaml, V.A. (1988), "Consumer perceptions of price, quality, and value: a means-end model and synthesis of evidence", Journal of Marketing, Vol. 52 No. 3, pp. 2-22. 